\title{
Season-dependent predictability and error growth dynamics for La Niña predictions
}

\author{
Junya $\mathrm{Hu}^{1} \cdot$ Wansuo Duan $^{2,3} \cdot$ Qian Zhou ${ }^{4}$
}

Received: 8 January 2018 / Accepted: 16 January 2019 / Published online: 24 January 2019

(c) The Author(s) 2019

\begin{abstract}
The "spring predictability barrier" (SPB) is a well-known characteristic of ENSO prediction, which has been widely studied for El Niño events. However, due to the nonlinearity of the coupled ocean-atmosphere system and the asymmetries between El Niño and La Niña, it is worthy to investigate the SPB for La Niña events and reveal their differences with El Niño. This study investigates the season-dependent predictability of sea surface temperature (SST) for La Niña events by exploring initial error growth in a perfect model scenario within the Community Earth System Model. The results show that for the prediction through the spring season, the prediction errors caused by initial errors have a season-dependent evolution and induce an SPB for La Niña events. Two types of initial errors that often yield the SPB phenomenon are identified: the first are type-1 initial errors showing positive SST errors in the central-eastern equatorial Pacific accompanied by a large positive error in the upper layers of the eastern equatorial Pacific. The second are type-2 errors presenting an SST pattern with positive errors in the southeastern equatorial Pacific and a west-east dipole pattern in the subsurface ocean. The type-1 errors exhibit an evolving mode similar to the growth phase of an El Niño-like event, while the type-2 initially experience a La Niña-like decay and then a transition to the growth phase of an El Niño-like event. Both types of initial errors cause positive prediction errors for Niño3 SST and under-predict the corresponding La Niña events. The resultant prediction errors of type-1 errors are owing to the growth of the initial errors in the upper layers of the eastern equatorial Pacific. For the type-2 errors, the prediction errors originate from the initial errors in the subsurface layers of the western equatorial Pacific. These two regions may represent the sensitive areas of targeted observation for La Niña prediction. In addition, the type-2 errors in the equatorial regions are enlarged by the recharge process from $10^{\circ} \mathrm{N}$ in the central Pacific during the eastward propagation. Therefore, the off-equatorial regions around $10^{\circ} \mathrm{N}$ in the central Pacific may represent another sensitive area of La Niña prediction. Additional observations may be prioritized in these identified sensitive areas to better predict La Niña events.
\end{abstract}

Keywords La Niña events · Spring predictability barrier · Initial errors

Wansuo Duan

duanws@lasg.iap.ac.cn

1 CAS Key Laboratory of Ocean Circulation and Waves, Institute of Oceanology, Chinese Academy of Sciences, Qingdao 266071, China

2 State Key Laboratory of Numerical Modeling for Atmospheric Sciences and Geophysical Fluid Dynamics (LASG), Institute of Atmospheric Physics, Chinese Academy of Sciences, Beijing 100029, China

3 University of Chinese Academy of Sciences, Beijing 100049, China

4 National Marine Environmental Forecasting Center, Ministry of Natural Resources, Beijing 100081, China

\section{Introduction}

The "spring predictability barrier" (SPB) is a well-known characteristic and still one remaining challenge for ENSO predictions. Commonly seen in both statistical and state-ofthe-art coupled models, the SPB refers to the strong seasonal dependence of ENSO predictability; that is, predictions initiated prior to the boreal spring always meet a steep decline in skill (Webster and Yang 1992; Latif et al. 1994; Yu and Kao 2007). Consequently, there are still considerable uncertainties in ENSO predictions and especially the operational seasonal forecasts generally cannot extend beyond 1-year lead time (Kirtman et al. 2002; Jin et al. 2008; Luo et al. 2005; Tippett et al. 2012; Barnston et al. 2012; Xue et al. 
2013, 2017), in spite of the remarkable progress made over the past decades.

Various hypotheses have been suggested to explain the occurrence of the SPB phenomenon. One perspective is that the SPB results from the annual cycle of the background state within the tropical coupled system (Zebiak and Cane 1987; Webster 1995; Levine and McPhaden 2015; Larson and Kirtman 2015). For example, Webster (1995) stated that the coupled system is frailest during the boreal spring, therefore is susceptible to random error growth and perturbations from external forcing such as monsoon. Some other studies argue the phase locking of ENSO as the cause of the SPB, because the lowest signal-to-noise ratio during the spring disrupts the ENSO persistence in this season (Xue et al. 1994; Balmaseda et al. 1995; Torrence and Webster 1998; Fan et al. 2000). Also, Clarke and Van Gorder (1999) and $\mathrm{Yu}$ (2005) emphasized that the biennial variability of ENSO is responsible for the phase locking and thus significantly enhances the barrier. Recently, Lopez and Kirtman (2014) and Larson and Kirtman (2016) have emphasized the role of stochastic forcing (e.g. WWB) in the occurrence of SPB.

In addition, a number of studies focus on the role of initial errors in the SPB. Chen et al. $(1995,2004)$ suggested that the breakdown of ENSO prediction skill in the spring arises from the growth of initial errors and thus improving initialization could eliminate the SPB. McPhaden (2003) demonstrated that additional predictive skill across the boreal spring for ENSO can be obtained by incorporating additional information from the Pacific subsurface temperature in initial conditions. Recently, Lee et al. (2017) indicated that the ocean initial errors at the thermocline in the western tropical Pacific grow rapidly and propagate to the east, resulting in the degradation of the ENSO prediction. By studying the initial error growth, Moore and Kleeman (1996) investigated the SPB phenomenon within a simple intermediate model using the linear singular vector (SV) method. The SV method extracts the leading SV as the fastest growing initial perturbation by using a tangent linear operator of nonlinear models, which, however, is difficult to obtain for general circulation models (GCMs). Kug et al. (2010) therefore developed an empirical singular vector (ESV) approach to obtain an approximation to the leading SV. The ESV is calculated by an empirical tangent linear operator, which is estimated empirically from historical data in a reduced space through an empirical orthogonal function (EOF) analysis. The ESV has been successfully applied to an intermediate coupled model and the Seoul National University (SNU) coupled GCM for ENSO studies (Kug et al. 2010, 2011; Ham and Rienecker 2012) and obtained useful results.

Both SV and ESV are in the framework of linear approximation to the nonlinear models, incapable of depicting fully the effects of nonlinearities. Mu et al. (2003) proposed a novel approach of conditional nonlinear optimal perturbation (CNOP), which involves nonlinearity and can describe the nonlinear evolution of initial perturbations. By using the CNOP method, Mu et al. (2007a, b) emphasized the importance of the optimally-growing initial error pattern in producing the SPB. They showed that the CNOPtype initial errors, compared with the leading SV-type initial errors, are more likely to cause a significant SPB for El Niño. They also illustrated that there exists some initial errors that cannot induce the SPB. Within the Zebiak-Cane model, Duan et al. (2009) recognized two types of CNOPtype initial errors, which show a zonal dipolar pattern for the sea surface temperature anomaly (SSTA) and a basin wide deepening or shoaling along the equator for the thermocline depth anomaly [also see Yu et al. (2009)]. Duan and Wei (2012) illustrated that such similar errors also exist in realistic hindcast predictions for El Niño. Using the Community Earth System Model (CESM), Duan and Hu (2016) further revealed the three-dimensional structure of sea temperature initial errors related to the SPB for El Niño prediction by an ensemble approach based on the CNOP idea. And these initial errors can also be observed in other coupled GCMs (Zhang et al. 2015).

From the above review, it can be seen that the SPB phenomenon of El Niño events has been extensively studied in previous work. However, there have been few efforts to discuss the predictability and the SPB phenomenon associated with La Niña events. Due to the complicated nonlinear processes in both the atmosphere and ocean, La Niña is not a simple mirror image of El Niño. In fact, several asymmetric aspects between El Niño and La Niña have been reported in the literature. Observations show that the amplitude of SSTA in the eastern equatorial Pacific during the mature phase of El Niño is typically larger than that during La Niña episodes (An and Jin 2004; Su et al. 2010; Im et al. 2015). This amplitude asymmetry, underestimated by most models from phase 5 of the Coupled Model Intercomparison Project (CMIP5), has also been noted in the subsurface fields of the tropical Pacific (Zhang et al. 2009a, b; Zhang and Sun 2014). In addition to the amplitude asymmetry, the duration and transition periods associated with El Niño and La Niña also are not symmetric. Typically, El Niño tends to decay rapidly by next spring or summer after the mature phase and is usually followed by a La Niña, but La Niña normally persists into the following year and intensifies in the subsequent winter, namely followed by another La Niña instead of an El Niño (Ohba and Ueda 2009; Okumura and Deser 2010; Hu et al. 2014, 2016). Okumura et al. (2011) suggested that these asymmetric transitions can be attributed to the asymmetric evolution of surface wind anomalies over the far western Pacific resulting from the nonlinear response of atmospheric deep convection to the SSTA during the mature phase of El Niño and La Niña. Zhang et al. (2009a, b) and McPhaden and Zhang (2009) also showed the asymmetry in 
the meridional extension of SSTA in the eastern equatorial Pacific and in the zonal propagation characteristics of El Niño and La Niña. Accordingly, El Niño and La Niña can bring different global impacts due to asymmetric teleconnection patterns (Hoerling et al. 1997; Zhang et al. 2014).

In view of the asymmetric characteristics between El Niño and La Niña, it can be referred that the predictability and the SPB phenomenon of La Niña events may bear distinctively different features compared to El Niño events. Therefore, it is necessary to explore the SPB phenomenon associated with La Niña and compare with El Niño to reveal their differences, thereby providing guidance for improving both El Niño and La Niña predictions. Actually, most of current models tend to exhibit a faster decline across the boreal spring in the forecasting skill for La Niña than El Niño (Jin et al. 2008; Lopez and Kirtman 2014). Duan and Wei (2012) showed that the SPB is most prominent for El Niño predictions whereas it is less prominent for La Niña predictions in realistic hindcast experiments. Nevertheless, it should be noted that their results are affected by both initial errors and model errors. As stated earlier, for El Niño events, Mu et al. (2007a, b) pointed out that initial errors with particular spatial characteristics are more likely to lead to the occurrence of SPB. As such, several questions arise: (1) Whether initial errors can induce an SPB for La Niña predictions? (2) Whether the SPB of La Niña relates to the spatial patterns of initial errors or not? If so, what are the spatial characteristics of these errors? (3) What are the dynamical mechanisms responsible for error development? To address these questions, in this study we will conduct perfect model predictability experiments to explore the season-dependent predictability of La Niña events from the perspective of initial error growth.

The rest of the paper is organized as follows. Section 2 describes the model, dataset and experimental strategy. In Sect. 3, the season-dependent evolution of prediction errors and the initial errors that often yield the SPB for La Niña predictions, and then the mechanisms responsible for the occurrence of the SPB are reported. Section 4 discusses the implications of the results. Finally, the main results are summarized and discussed in Sect. 5.

\section{Model, dataset and experiments}

The model adopted in this study is the Community Earth System Model (CESM) from the National Center for Atmospheric Research (NCAR). The model is comprised of an ocean, atmosphere, land, sea-ice and ice sheet models, all connected through a flux coupler. For this work, the atmosphere component, the Community Atmosphere Model version 4 (CAM4), has horizontal resolution $0.9^{\circ} \times 1.25^{\circ}$ on the regular longitude-latitude grid. The ocean component is the Parallel Ocean Program version 2 (POP2), the horizontal resolution of which is approximately $1^{\circ}$ in the longitude and variable in the latitude direction with finer resolution, about $0.27^{\circ}$, near the equator. The ocean has 60 vertical levels with layer spacing monotonically increasing from 10 to $250 \mathrm{~m}$ with depth. A detailed description of the CESM coupling infrastructure maybe found in Hurrell et al. (2013) and Kay et al. (2015).

Most of current models are limited to reproduce realistic La Niña events, especially the phase locking feature of $\mathrm{La}$ Niña events that is closely related to the SPB as reviewed in the introduction, and the CESM is no exception. Duan and $\mathrm{Hu}(2016)$ noted that the 150-year control simulation of the CESM cannot well model the phase-locked La Niña events. Nevertheless, they revealed the optimal precursory disturbances of La Niña events by using the same model (Hu and Duan 2016). The La Niña events triggered by these optimal precursory disturbances generally attain their peak values at the end of the year, bearing a good feature of phase-locking. Therefore, in this study, we will explore the seasondependent predictability of La Niña events on the basis of their work. Specifically, from the La Niña events developed from optimal precursory disturbances, six La Niña events are randomly selected as the "true state" to be predicted for this study. Figure 1 shows the time-dependent Niño3 indices for the six La Niña events, which present the phase-locking characteristic consistent with that in observations.

The Extended Reconstructed Sea Surface Temperature analysis version 3 (ERSST V3) (Smith et al. 2008) is used to verify the simulated La Niña events. The observed climatology is averaged over the 1971 and 2010 year. Comparatively, a composite analysis for the observed La Niña events and the six selected La Niña events is shown in Fig. 2.

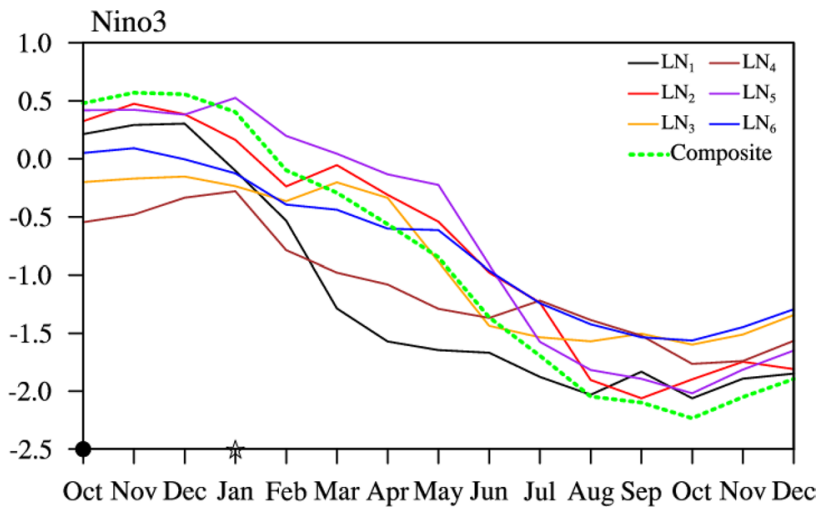

Fig. 1 Niño3 indices of the six "true state" La Niña events, denoted by $\mathrm{LN}_{\mathrm{i}}(\mathrm{i}=1 \ldots 6)$. The green dished line represents the composite of the six La Niña events. The black point denotes the start month of October $(-1)$ in the year preceding the La Niña year. The star denotes the start month January (0) of the La Niña year 
(a) OBS

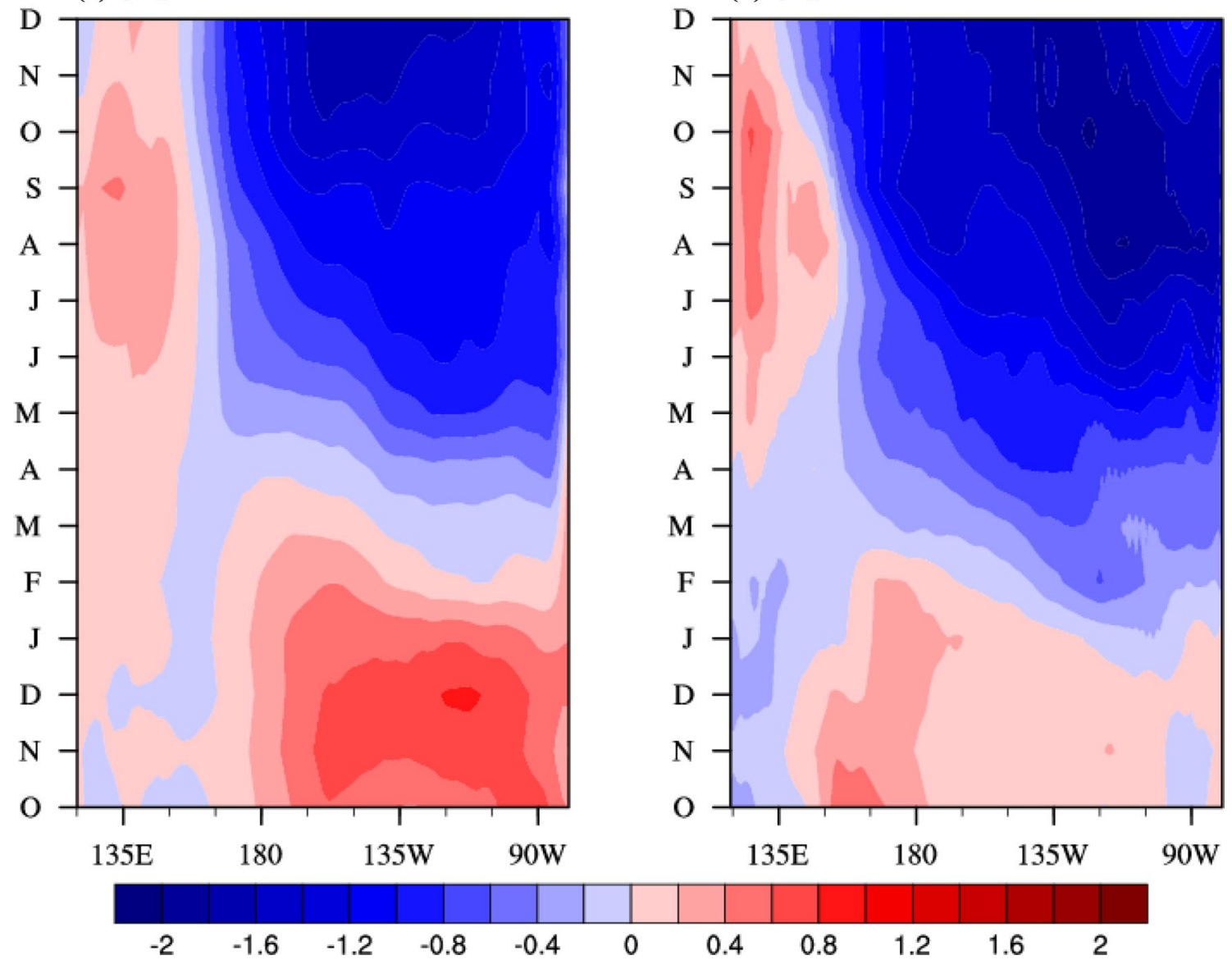

Fig. 2 Time and longitude evolutions of SST anomalies $\left({ }^{\circ} \mathrm{C}\right)$ averaged between $5^{\circ} \mathrm{S}-5^{\circ} \mathrm{N}$ for composite of a observed and $\mathbf{b}$ modeled La Niña years. The observed La Niña years are 1973/74, 1975/76,

The predictions for the "true state" La Niña events are made by integrating the model for 12 months with perturbed initial fields from the start months of October $(-1)$ and January (0), where " -1 " denotes the year preceding the La Niña year and "0" denotes the La Niña year. For each La Niña event, the initial errors are superimposed on the sea temperature initial fields in the tropical Pacific Ocean $\left(20.19^{\circ} \mathrm{S}-20.05^{\circ} \mathrm{N}, 130.44^{\circ} \mathrm{E}-84.49^{\circ} \mathrm{W}\right)$ extending from the surface to $165 \mathrm{~m}$ depth in order to include subsurface temperature information. The initial errors are generated by taking the differences between the sea temperature of La Niña events at the starting month and the temperatures in each month of the 3 years preceding the $\mathrm{La}$ Niña year. For each La Niña event, there obtain 36 initial errors at each starting month. Thus, there are a total of 432 predictions for the six La Niña events corresponding to 432 initial errors.

The prediction errors are characterized by the difference between the "true state" La Niña and its predictions, which are caused only by initial errors in the perfect model predictability
1988/89, 1999/2000, 2007/08 and 2010/11. The composites range from October of the year before the La Niña to December of the La Niña peaking year

experiments. The magnitude of prediction errors for Niño3 SST of La Niña events is measured by

$T^{\prime}(t)=\left\|T^{p}(t)-T^{t}(t)\right\|=\sqrt{\frac{\sum_{i, j}\left[T_{i, j}^{p}(t)-T_{i, j}^{t}(t)\right]^{2}}{N}}$

where $T^{p}(t)$ and $T^{t}(t)$ represent the "predicted" and "true" SST, $(i, j)$ are the grid points in the Niño3 region and $N$ is the total grid number in the Niño3 region.

Specifically, to investigate the season-dependent predictability of SST, a year is divided into four seasons: January to March (JFM), April to June (AMJ), and so forth. Then, the growth tendency $\kappa$ of prediction errors can be evaluated by

$\kappa=\frac{\partial T^{\prime}(t)}{\partial t} \approx \frac{T^{\prime}\left(t_{2}\right)-T^{\prime}\left(t_{1}\right)}{t_{2}-t_{1}}$

where $T^{\prime}\left(t_{2}\right)$ and $T^{\prime}\left(t_{1}\right)$ denote the prediction errors at the end of a season $t_{2}$ and at the start time of the season $t_{1}$ respectively. Therefore, a positive (negative) value of $\kappa$ corresponds 
to an increase (decrease) of errors, and the larger the absolute value of $\kappa$, the faster the increase (decrease) of errors.

In addition, to investigate the uncertainties caused by the initial errors of La Niña prediction, the prediction errors for Niño3 index, denoted as "L-Niño3", are determined by

$\mathrm{L}-\mathrm{Niño3}=\operatorname{avg}\left[\mathrm{T}_{i, j}^{p}(\mathrm{t})\right]-\operatorname{avg}\left[T_{i, j}^{t}(\mathrm{t})\right]$

where $T^{p}(t), T^{t}(t)$ and $(i, j)$ are same as in Eq. (1). That is, L-Niño3 represents the difference between the Niño3 indices of the "true state" La Niña events and those of predicted ones. A positive (negative) value of L-Niño3 shows a positive (negative) prediction error in Niño3 SST and indicates an under-prediction (over-prediction) of the La Niña event.

\section{Results}

In this section we present the results of the analysis of the season-dependent evolution of Niño3 SST prediction errors, and identify the dominant spatial characteristics of initial errors that often induce an SPB for La Niña events. Then, the physical mechanism for the error growth associated with the SPB of La Niña is explored by tracing the evolution of these initial errors.

\subsection{Spatial patterns of SPB-related initial errors for La Niña events}

According to the Sect. 2, the prediction errors of the Niño3 SST for each La Niña event and corresponding error growth tendency are calculated by using Eqs. (1) and (2). As stated earlier, there are 432 predictions for the start months October (-1) and January (0) of the six La Niña events. The occurrence of an SPB means that there is a large prediction error and it grows fastest in spring (Mu et al. 2007a, b; Duan et al. 2009). Based on this, from the 432 predictions, it is found that there are 60 predictions for the start month October (-1) and 51 for January (0) that yield the SPB phenomenon of La Niña (Table 1). Figure 3 shows the evolution of the prediction errors of Niño3 SST and the ensemble mean of their seasonal growth tendency $\kappa$ corresponding to these predictions. It can be seen that for both start months of October $(-1)$ and January (0), the prediction errors exhibit largest growth tendency in the AMJ season, showing a season-dependent evolution, and induce an SPB phenomenon. In addition, in Fig. 3 the L-Niño3 indicate that the SPB-related initial errors tend to yield a large positive error of Niño3 SST and usually cause the La Niña events to be under-predicted.

As discussed above, one hundred and eleven initial errors are identified to present significant growth in spring and cause large prediction errors of La Niña events and hence signified as the SPB-related initial errors for La Niña predictions. To explore the dominant spatial patterns of these initial errors, we performed Combined Empirical Orthogonal Function (CEOF) analysis of these initial errors and obtained the leading CEOF mode (i.e., CEOF1, responsible for $32.5 \%$ of the total variance) and its time series (i.e., $\mathrm{PC} 1)$. The $\mathrm{PC} 1$ presents positive and negative values, which indicate that the dominant mode of SPB-related initial errors exhibits either a CEOF1 pattern or its opposite pattern. To classify the SPB-related initial errors, we went back to the original one hundred and eleven SPB-related initial errors and, according to the positive and negative values of PC1, divided them into two groups. Then the composite patterns of the two groups of initial errors are referred to as type-1 and type-2 SPB-related initial errors, respectively. Figure 4 shows the composite spatial patterns of the SST and subsurface temperature components of the two types of initial errors. For the type-1 initial errors, they present positive SST errors in the central-eastern equatorial Pacific and a large positive subsurface temperature error in the upper layers of the eastern equatorial Pacific. For the type-2 errors, the sea temperature shows positive errors in the surface layer of the southeastern equatorial Pacific and a west-east dipole pattern in the subsurface layer along the equator. Speciaifically, the type-2 initial errors show positive errors of the SST component in the eastern equatorial Pacific and negative errors of the subsurface sea temperature in the eastern Pacific accompanied by positive subsurface sea temperature errors in the lower layers of the western equatorial Pacific. The prediction errors induced by the type- 1 and type- 2 initial errors are shown in Fig. 5. It shows that both types of initial errors, in spite of their different spatial patterns, cause La Niña events to be under-predicted (Fig. 4). Nevertheless, the prediction errors caused by type- 2 initial errors are somewhat larger than those caused by type- 1 initial errors.
Table 1 The numbers of initial errors that induce the SPB phenomenon for La Niña events

\begin{tabular}{lcccccrr}
\hline & $\mathrm{LN}_{1}$ & $\mathrm{LN}_{2}$ & $\mathrm{LN}_{3}$ & $\mathrm{LN}_{4}$ & $\mathrm{LN}_{5}$ & $\mathrm{LN}_{6}$ & Total \\
\hline October (-1) & 7 & 11 & 11 & 7 & 10 & 14 & 60 \\
January (0) & 15 & 6 & 8 & 5 & 10 & 7 & 51 \\
Total & 22 & 17 & 19 & 12 & 20 & 21 & 111 \\
\hline
\end{tabular}

$\mathrm{LN}_{\mathrm{i}}(\mathrm{i}=1, \ldots 6)$ denote the six La Niña events. There are 36 initial errors for each La Niña and a total of 432 errors, in which 60 induce SPB for the start month October $(-1)$ and 51 for January (0) 
(a) Oct(-1)


Fig. 3 Upper panels: the evolution of prediction errors of Niño3 SST, $T^{\prime}(t)$, caused by the SPB-related initial errors (curves) and the ensemble mean of seasonal growth rate $\kappa$ (histograms). Lower panels: the (b) $\operatorname{Jan}(0)$
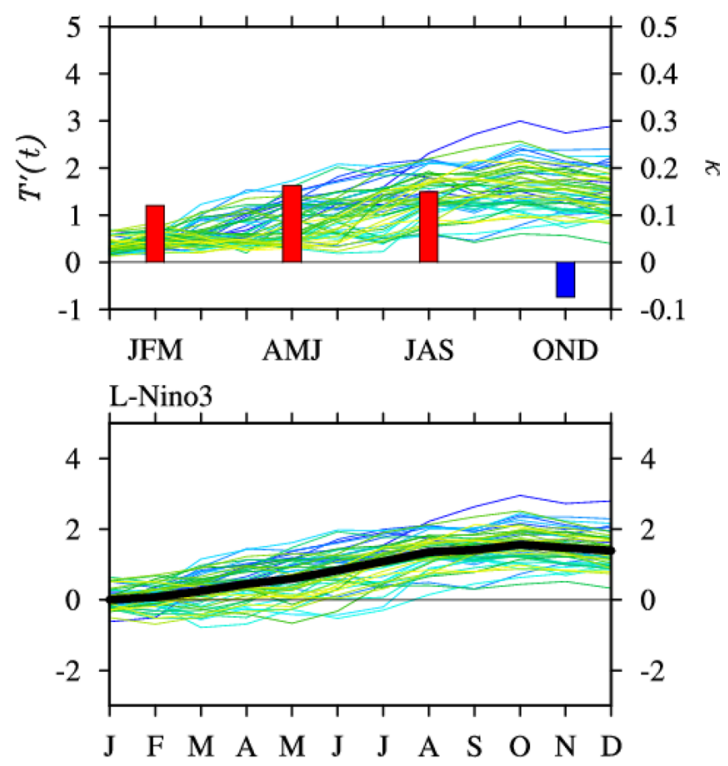

corresponding prediction errors of Niño3 index, L-Niño3 (curves) and their ensemble mean (thick black line). The start months of the predictions are $\mathbf{a}$ October $(-1)$ and $\mathbf{b}$ January (0) (a) SST
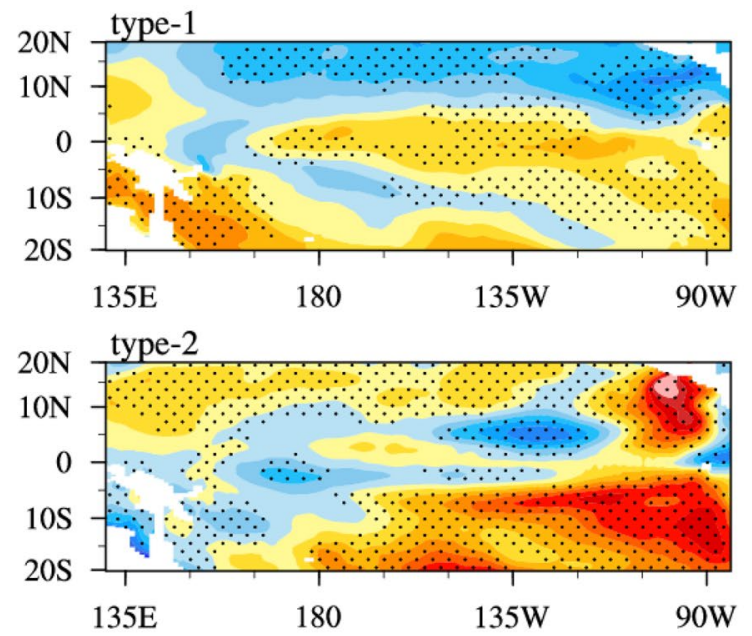

(b) Subsurface sea emperature
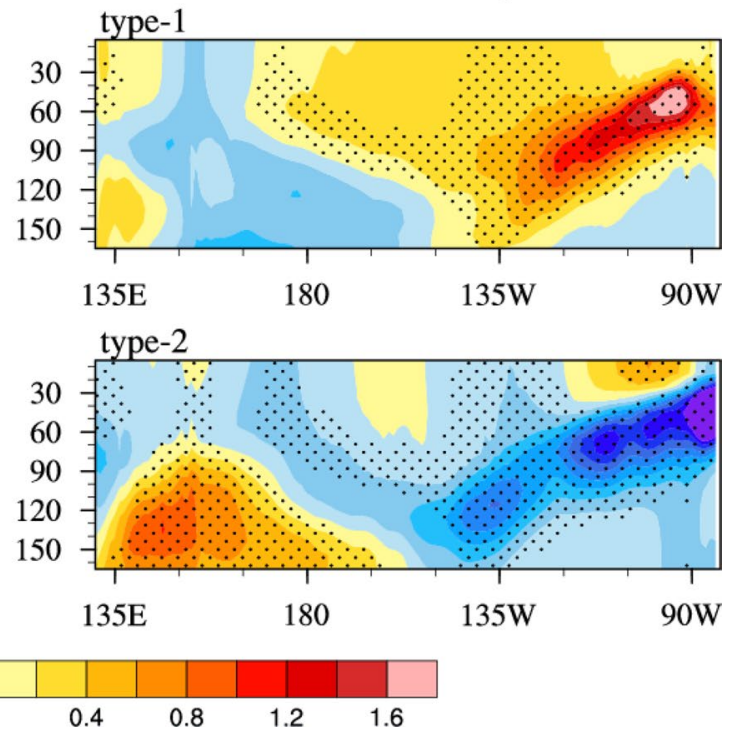

Fig. 4 Spatial patterns of a SST and b equatorial $\left(5^{\circ} \mathrm{S}-5^{\circ} \mathrm{N}\right)$ subsurface temperature components of SPB-related initial errors for La Niña predictions. The upper panel is the type- 1 initial errors, and the lower panel is the type- 2 initial errors. Dotted areas indicate that the composites of SST and subsurface temperature errors pass the $99 \%$ significance level estimated by a t test

with those obtained in the last paragraph. From Sect. 2, it is known that there are a total of 432 initial errors for predicting six La Niña events. To calculate the ESV, we use these initial errors and their resulted prediction errors to estimate the empirical tangent linear operator in a reduced space through an EOF analysis. The EOF analysis is applied to the 


\section{(a) type-1}

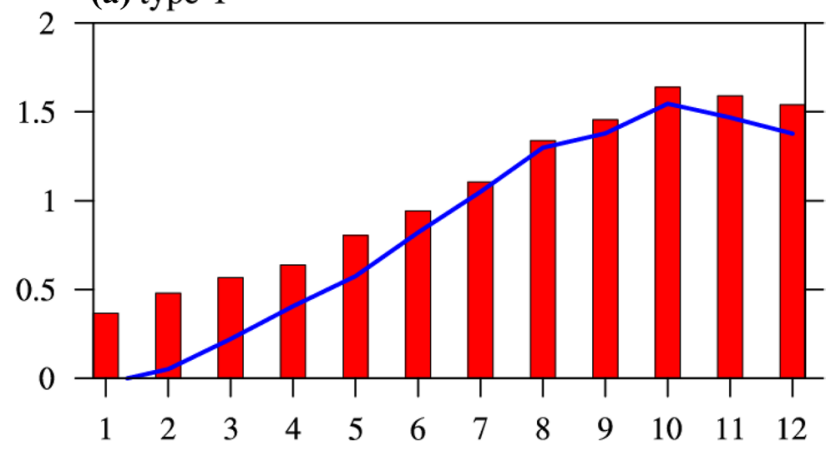

(b) type-2

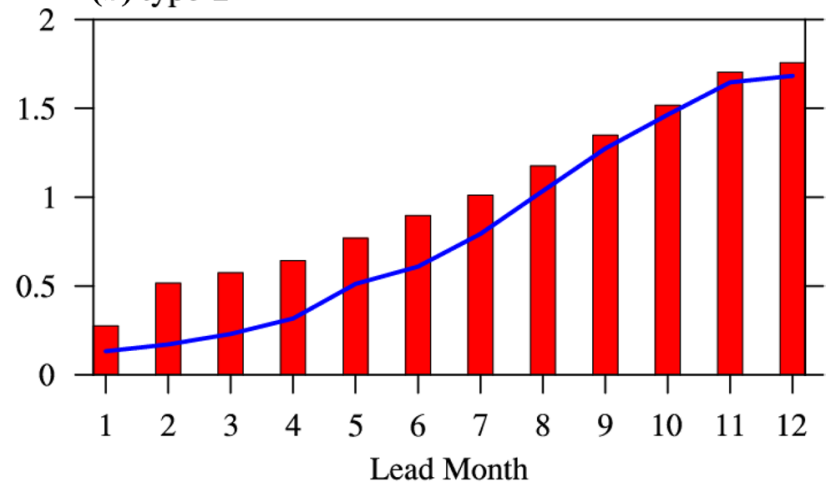

Fig. 5 Prediction errors of SST $\left(T^{\prime}(t)\right.$, histogram) and Niño3 index, (L-Niño3, curves) caused by the a type-1 and b type-2 SPB-related initial errors

corresponding ocean heat content component of the initial sea temperature errors and then the prediction errors of the SST with lead time 12 months. The leading six EOF modes of initial heat content errors and prediction errors of SST are taken to estimate the tangent linear operator, which explain
$82.7 \%$ and $75.8 \%$ of the total variance of the ocean heat content and SST errors, respectivey. Their principle components can be respectively formulated into matrix $X$ and $Y$ with a $6 \times 432$ arrary. According to Kug et al. (2011), the empirical tangent linear operator can be estimated by $L=Y X^{T}\left(X X^{T}\right)^{-1}$ and finally obtain the matrix $L$ with a $6 \times 6$ arrary. By performing a singular value decomposition, the matrix $L$ can be written as $L=U S V^{T}$. The vectors $V$ and $U$ are then acted on the leading six EOF modes of initial heat content errors and related prediction errors for SST component, finally achieving the leading six ESVs of initial heat content errors and prediction errors of SST, respectively. After obtaining these ESVs, the initial SST error of the ESVs can be easily obtained through a linear regression. Furthermore, the largest singular value (i.e. the largest characteristic value of the matrix $S$ ) is 1.34 , which is larger than 1 and indicates that the corresponding ESV including initial SST and ocean heat content errors grows quickly and acts as an approximation of the fastest growing mode. Figure 6 shows this leading ESV. It is shown that both ocean heat content and SST components of the initial errors show weak warm anomalies in the central-eastern equatorial Pacific. Such ESV mode develops into a dipole mode of ocean heat content along the tropical Pacific and presents large positive SST anomaly in the eastern tropical Pacific at the lead time 12 months, finally formulating an El Niño-like event.

It has been shown that the type- 1 initial errors show positive SST errors and a large positive subsurface temperature error in the eastern equatorial Pacific (Fig. 4), and they tend to evolve like a development of an El Niño event (see Sect. 3.2). To compare the leading ESV and the type-1 error, we illustrate them in Fig. 7 with the SST and ocean heat content components and the corresponding 12-month lead prediction errors of SST and ocean heat content. It can be

\section{(a) Initial SST of ESV}

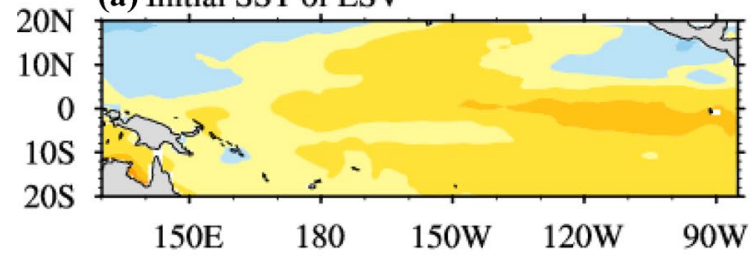

(c) Final SST of ESV
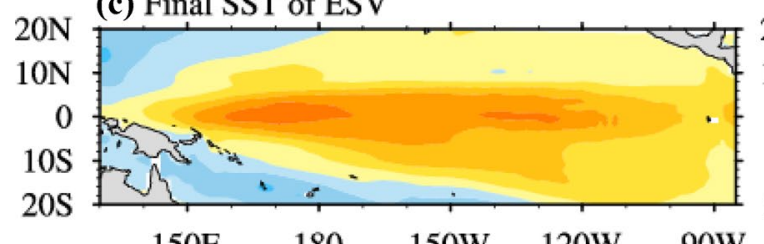

$$
150 \mathrm{E} \quad 180 \quad 150 \mathrm{~W} \quad 120 \mathrm{~W} \quad 90 \mathrm{~W}
$$

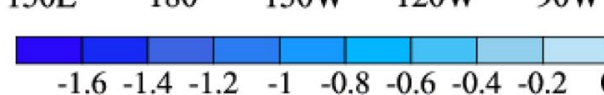

\section{(b) Initial OHC of ESV}

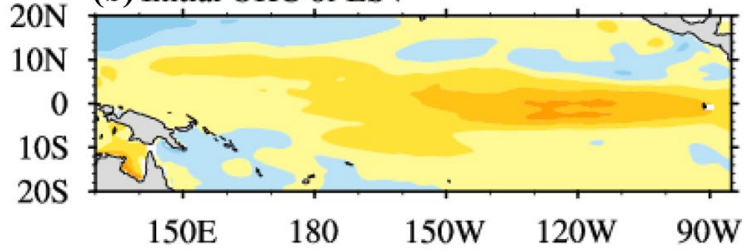

(d) Final OHC of ESV

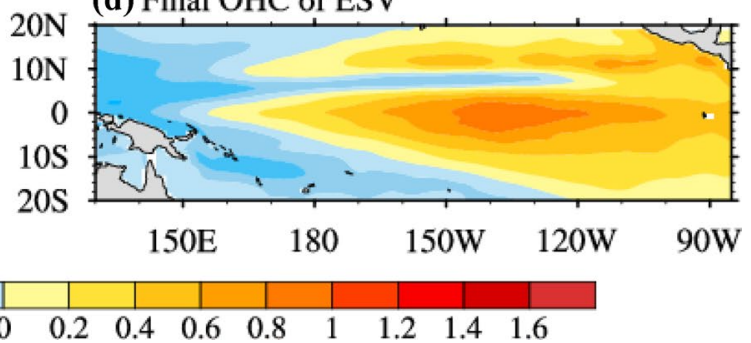

Fig. 6 First leading singular mode of initial error of $\mathbf{a}$ SST and $\mathbf{b}$ ocean heat content and final prediction error of $\mathbf{c}$ SST and $\mathbf{d}$ ocean heat content 
(a) Initial SST of type-1

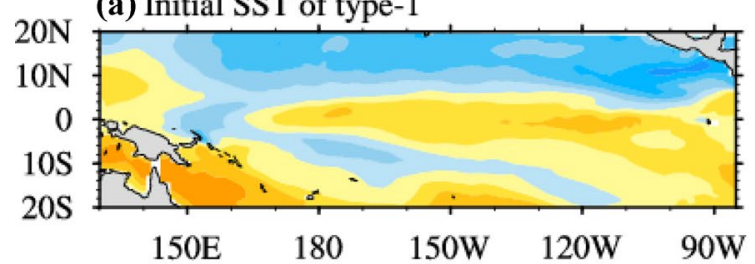

(c) Final SST of type-1
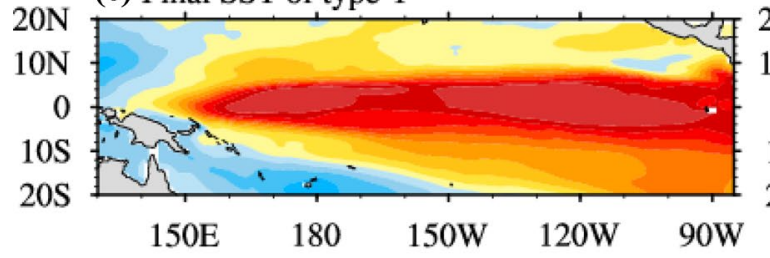

(b) Initial OHC of type-1

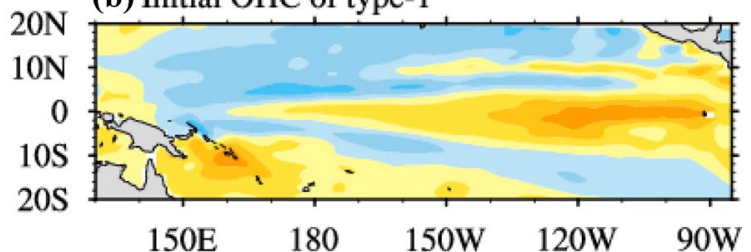

(d) Final OHC of type-1
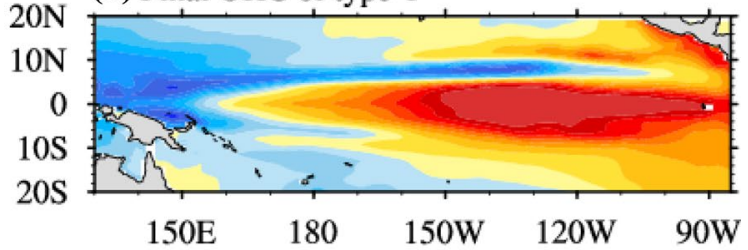

$\begin{array}{lllllllllllllllll}-1.6 & -1.4 & -1.2 & -1 & -0.8 & -0.6 & -0.4 & -0.2 & 0 & 0.2 & 0.4 & 0.6 & 0.8 & 1 & 1.2 & 1.4 & 1.6\end{array}$

Fig. 7 Spatial patterns of type-1 initial errors of a SST and $\mathbf{b}$ ocean heat content, and 12-month lead prediction errors of $\mathbf{c}$ SST and $\mathbf{d}$ ocean heat content

seen that the spatial structure of the leading ESV and the type-1 error bears similarity; however, the amplitude of SST prediction errors caused by the type- 1 initial errors is larger than that caused by the leading ESV error. In addition, the type-1 initial errors yield somewhat smaller prediction error than the type-2 initial errors (Fig. 5). It may therefore suggest that the leading ESV partially captures the characteristics of the relatively slowly-growing one of the two types of initial errors obtained in the present study. So we still use the two types of initial errors, rather than the ESV, to perform the following analysis.

\subsection{Dynamical growth of SPB-related initial errors for La Niña events}

In Sect. 3.1, it has been demonstrated that there exist two types of initial errors that yield an SPB phenomenon for La Niña predictions. This section investigates the growth dynamical behaviors for these errors and reveals the physical mechanisms of error growth. Figure 8 shows the evolution of prediction errors of SST and surface wind stress caused by type- 1 and type- 2 initial errors, which are composite difference between the predictions and the corresponding "true state" La Niña events. By observing the evolution of the prediction errors, we find that the positive SST errors of the type- 1 error show sustained growth over the central-eastern equatorial Pacific during the prediction period, eventually developing into an El Niño-like event. For the type-2 error, there initially exists a weak negative SST error in the eastern equatorial Pacific but disappears rapidly and transits into an El Niño-like evolving mode. That is to say, both the type-1 and type- 2 initial errors are inclined to under-predict the magnitude of La Niña events.
From Fig. 8a, when the type-1 initial errors disturb the initial state of a La Niña event, a positive SST error occurs in the central-eastern equatorial Pacific, which triggers a westerly perturbation and the Bjerknes positive feedback establishes to favor the warming in the eastern equatorial Pacific. Meanwhile, the large but positive initial errors located in the subsurface layer of the eastern equatorial Pacific further contribute to the surface warming by transporting warm water upward through the mean upwelling (Fig. 9a). As a result, the initial warming errors in the eastern equatorial Pacific continually amplify and evolve into a mature El Niño-like mode at the prediction time. That is, the type-1 errors exhibit an evolving mode similar to the growth phase of an El Niñolike event.

In the case of the type- 2 initial errors, the initial positive subsurface temperature anomaly induces a thermocline deepening in the western equatorial Pacific, which propagates eastward by generating a downwelling Kelvin wave and weakens the initial cold subsurface error in the eastern Pacific. Afterwards, the cold error gradually decreases and favors the surface warming in the eastern Pacific (Fig. 9b). When the warming due to the Kelvin wave occurs, it turns out to be that the Bjerknes feedback is critical for the subsequent error growth, eventually resulting in an El Niño-like event. Therefore, the type-2 errors tend to experience a process similar to a rapid decay of La Niña prior to a transition to the growth phase of an El Niño-like event. However, it should be noted that, in Fig. 9b, the initial subsurface warm error in the western Pacific becomes very weak within two months after prediction, while in the third month the positive anomalies re-intensify near the dateline. Obviously, the amplification 
(a) type-1
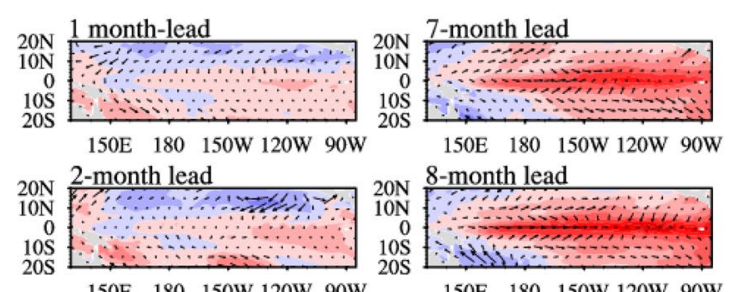

$150 \mathrm{E} \quad 180 \quad 150 \mathrm{~W} 120 \mathrm{~W} 90 \mathrm{~W}$ 20N 3-month lead

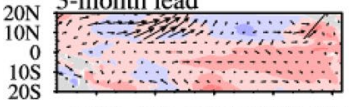

$150 \mathrm{E} \quad 180 \quad 150 \mathrm{~W} 120 \mathrm{~W} 90 \mathrm{~W}$

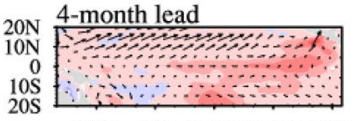

$150 \mathrm{E} \quad 180$ 150W 120W 90W

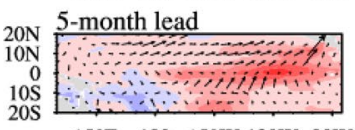

$150 \mathrm{E} \quad 180 \quad 150 \mathrm{~W} 120 \mathrm{~W} 90 \mathrm{~W}$ 6-month lead

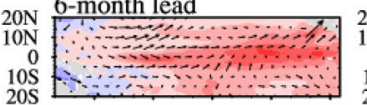

$150 \mathrm{E} \quad 180 \quad 150 \mathrm{~W}$ 120W 90W

$\begin{array}{llll}150 \mathrm{E} & 180 & 150 \mathrm{~W} 120 \mathrm{~W} 90 \mathrm{~W}\end{array}$ 8-month lead

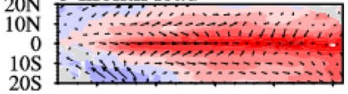

$150 \mathrm{E} \quad 180$ 150W 120W 90W

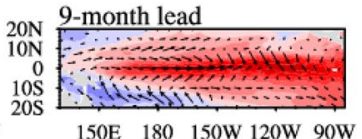

10-month lead

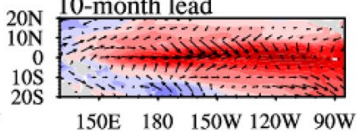

$150 \mathrm{E} \quad 180 \quad 150 \mathrm{~W} 120 \mathrm{~W}$ 90W

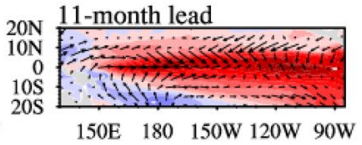

12-month lead

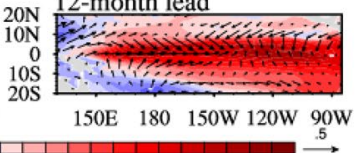

(b) type-2
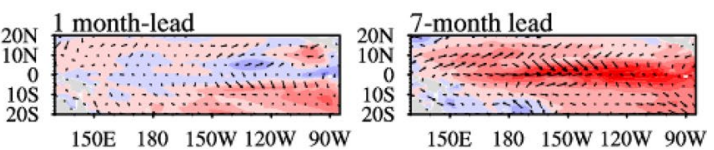

$20 \mathrm{~N}$ 2-month lead

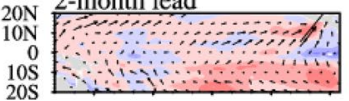

$150 \mathrm{E} \quad 180$ 150W 120W 90W

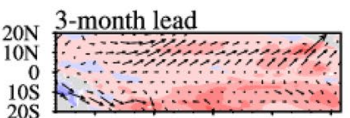

$150 \mathrm{E} \quad 180 \quad 150 \mathrm{~W} 120 \mathrm{~W} 90 \mathrm{~W}$

4-month lead

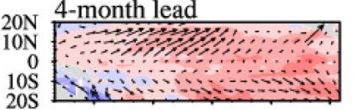

150E 180 150W 120W 90W

$20 \mathrm{~N} 5$-month lead

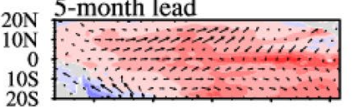

150E 180 150W 120W 90W $20 \mathrm{~N}$ 6-month lead

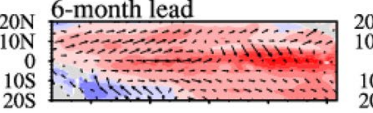

$150 \mathrm{E} \quad 180 \quad 150 \mathrm{~W} 120 \mathrm{~W} 90 \mathrm{~W}$

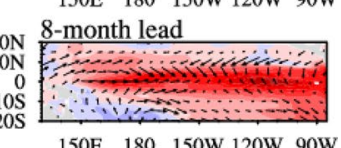

150E 180 150W 120W 90W

$20 \mathrm{~N}$ 9-month lead

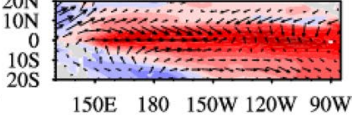

$150 \mathrm{E} \quad 180 \quad 150 \mathrm{~W} 120 \mathrm{~W} 90 \mathrm{~W}$
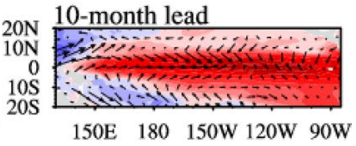

$150 \mathrm{E} \quad 180 \quad 150 \mathrm{~W} 120 \mathrm{~W}$ 90W

$20 \mathrm{~N}$ 11-month lead

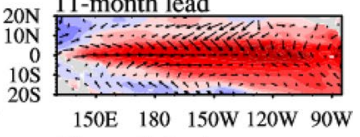

12-month lead

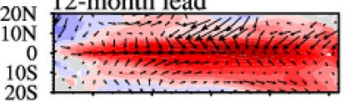

$150 \mathrm{E} \quad 180 \quad 150 \mathrm{~W} 120 \mathrm{~W}$ 90W

$150 \mathrm{E} \quad 180 \quad 150 \mathrm{~W} 120 \mathrm{~W} 90 \mathrm{~W}$

Fig. 8 Evolutions of SST (shading) and surface wind stress (vector, units: dyn/ $\mathrm{cm}^{2}$ ) prediction errors over the tropical Pacific Ocean caused by a type-1 and b type-2 SPB-related initial errors for La Niña events

of this warm error and its eastward propagation through Kelvin wave are critical for the warming in the eastern equatorial Pacific at the prediction time. It is natural to ask that how this positive subsurface anomaly near the dateline becomes intensified. To address this, we analyze the evolution of the zonal wind stress and ocean heat content between the surface and the $165 \mathrm{~m}$ depth in Fig. 10 . It shows that there exists a center of warm water around $10^{\circ} \mathrm{N}$ in the central Pacific. From Fig. 8b, we know that there is an initial SST warming in the southeastern Pacific for the type- 2 errors, which can induce a westerly anomaly in the central-eastern Pacific and lead to a recharge process to the equatorial region, following the recharge oscillator paradigm (Jin 1997a, b). Consequently, the warm anomaly near the dateline is intensified gradually due to the recharge process. A comparison between type- 1 and type- 2 errors indicates that both types of initial errors develop into an El Niño-like mode and induce an underprediction of the corresponding La Niña events. However, different from the type- 1 error growth mainly confined in the equatorial region (i.e. $5^{\circ} \mathrm{S}-5^{\circ} \mathrm{N}$ ) during the prediction period, the growth of the type- 2 errors is also owing to the recharge progress of the warm errors around $10^{\circ} \mathrm{N}$ in the central Pacific and afterwards due to the ocean waves and Bjerknes feedback in the equatorial regions.

\section{Implications}

We have demonstrated that there exist two types of initial errors that show season-dependent evolutions with rapid growth occurring in the AMJ season, which are related to the SPB phenomenon of La Niña events. Especially, it is noticed that the growth of the positive prediction errors of the Niño3 SST caused by the type- 1 initial errors is mainly owing to the upward transport of warm water from the subsurface ocean in the eastern equatorial Pacific combined with Bjerknes feedback between SST and zonal wind anomalies. In this sense, reducing the initial errors in the upper layers of the eastern equatorial Pacific may greatly improve La Niña predictions. In terms of the type- 2 errors, the positive errors of the Niño3 SST are mainly induced by the eastward propagation of the initial positive errors in the subsurface layers of the western equatorial Pacific and the subsequent enlarged errors in the eastern Pacific. As such, it suggests that $\mathrm{La}$ Niña predictions may also be sensitive to the initial errors in the subsurface layers of the western equatorial Pacific. Therefore, the forecast skill of La Niña could be greatly improved if we give the priority to improve the accuracy of initial field in the areas of the upper layers of the eastern equatorial Pacific and the lower layers of the western equatorial Pacific. In addition, during their eastward propagation, the type- 2 errors in the equatorial regions are enlarged by 
(a) type-1
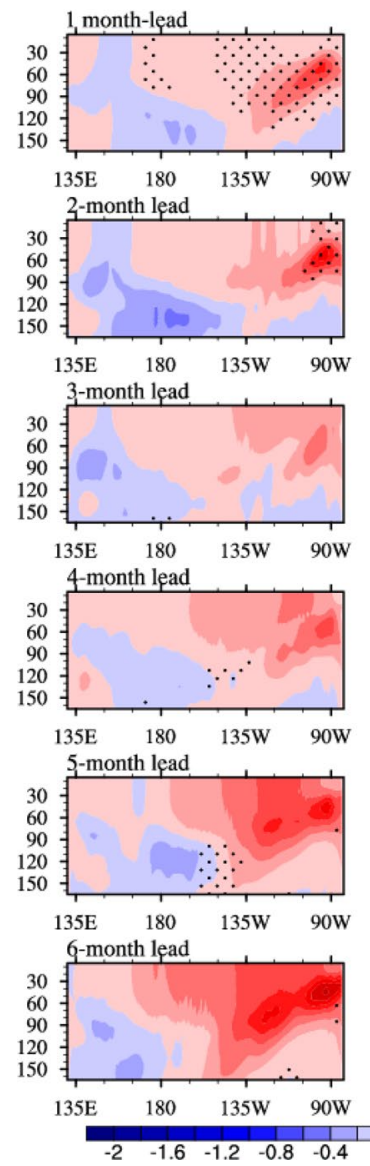
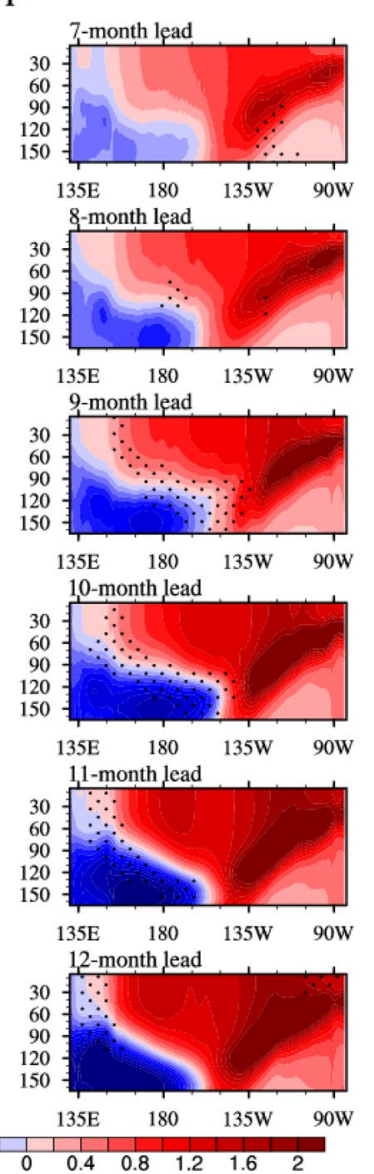

(b) type-2
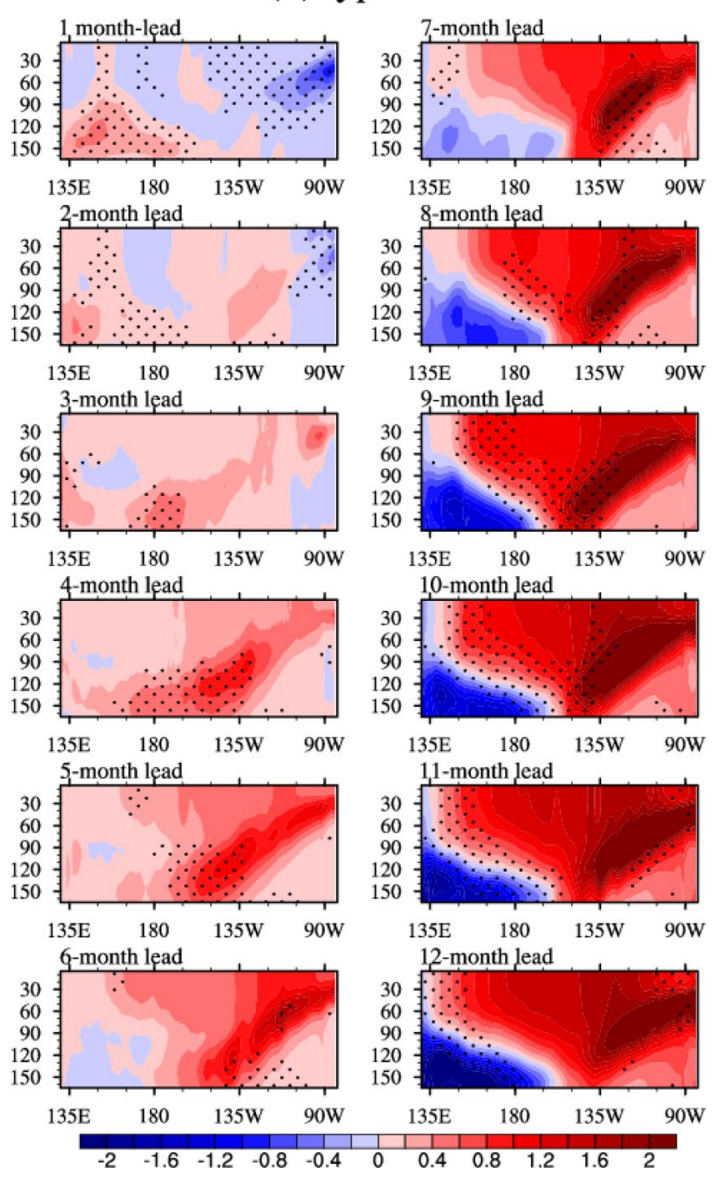

Fig. 9 Evolutions of equatorial $\left(5^{\circ} \mathrm{S}-5^{\circ} \mathrm{N}\right)$ subsurface temperature prediction errors caused by a type- 1 and $\mathbf{b}$ type- 2 SPB-related initial errors for La Niña events. Dotted areas indicate that the composite subsurface temperature errors pass the $95 \%$ significance level estimated by a t test

the recharge process from $10^{\circ} \mathrm{N}$ in the central Pacific. Therefore, the off-equatorial regions around $10^{\circ} \mathrm{N}$ in the central Pacific may represent another important area of improving initial field accuracy for La Niña prediction. The accuracy of the initial fields can be improved by deploying targeted observations (Mu 2013). From the above analysis, it is easily inferred that the upper layers of the eastern equatorial Pacific, the lower layers of the western equatorial Pacific, and the off-equatorial regions around $10^{\circ} \mathrm{N}$ in the central Pacific could be candidates for the areas where the targeted observations should be preferentially deployed.

The above areas for targeted observations are consistent with the key regions responsible for the onset and development of La Niña events. It is well known that large-scale interactions between the atmosphere and ocean are responsible for La Niña onset and development (Bjerknes 1969). Following the framework of recharge-discharge theory, the anomaly information in the subsurface layers of the western equatorial Pacific is generated by recharge/discharge process from the off-equatorial regions. Then these anomalies induce remote and local effects on SSTs in the eastern equatorial Pacific through oceanic equatorial wave processes. In addition, surface winds response to the SSTAs in the eastern equatorial Pacific, playing an important role in forcing the ocean. Therefore, additional observations in the subsurface layers of the western equatorial Pacific and the off-equatorial regions around $10^{\circ} \mathrm{N}$ in the central Pacific may greatly help capture the initial anomaly signal for La Niña onset, while targeted observations deployed in the upper layers of the eastern equatorial Pacific contribute to trace the subsequent development of La Niña, thereby greatly improving La Niña prediction.

\section{Summary and discussion}

By conducting perfect model predictability experiments using the CESM model, this study explores the seasondependent evolution of initial error growth for La Niña predictions and investigates the spatial characteristics of the 
(a) TAUX

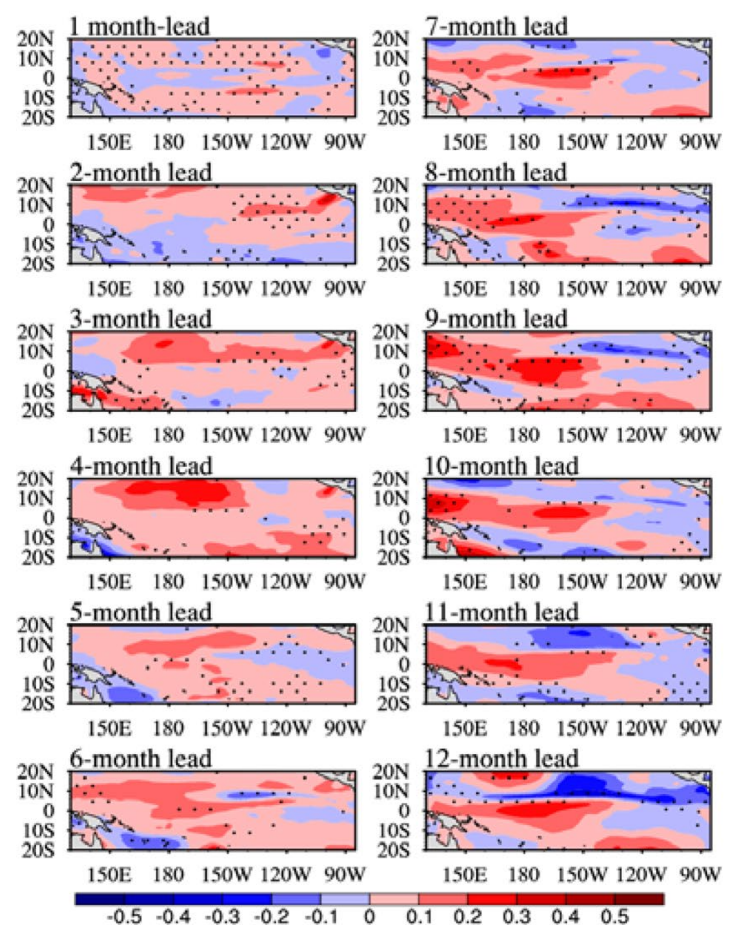

(b) $\mathrm{OHC}$
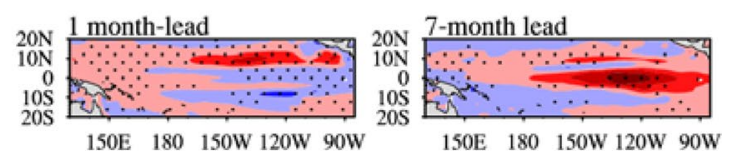
$20 \mathrm{~N}$ 2-month lead

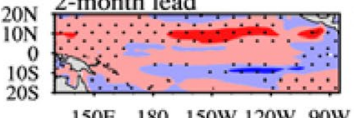

$150 \mathrm{E} \quad 180 \quad 150 \mathrm{~W} 120 \mathrm{~W}$ 90w $20 \mathrm{~N} 3$-month lead

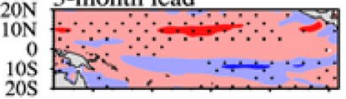

$150 \mathrm{E} 180150 \mathrm{~W} 120 \mathrm{~W}$ 90W $20 \mathrm{~N}$-month lead

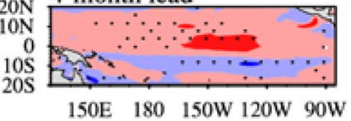

5 -month lead

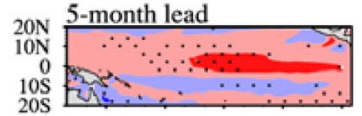

150E $180150 \mathrm{~W} 120 \mathrm{~W} 90 \mathrm{~W}$

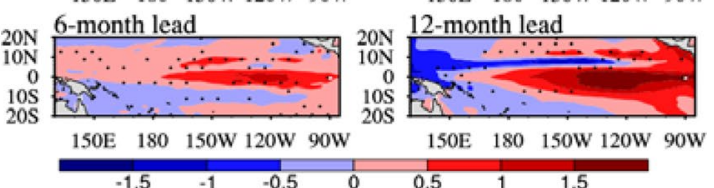

Fig. 10 Evolutions of a zonal wind stress (units: dyn $/ \mathrm{cm}^{2}$ ) and $\mathbf{b}$ ocean heat content prediction errors for type-2 errors. Dotted areas indicate that the composite prediction errors pass the $95 \%$ significance level estimated by a t test

initial errors that often induce an SPB for La Niña predictions. The results indicate that two types of initial errors show season-dependent evolution, with the rapid growth occurring during April through June irrespective of the start month, and tend to induce the SPB phenomenon of La Niña events. The type-1 initial errors present positive SST errors in the central-eastern equatorial Pacific accompanied by a large positive subsurface temperature error in the upper layers of the eastern equatorial Pacific. The type-2 errors show positive SST errors in the southeastern equatorial Pacific and a west-east dipole pattern in the subsurface ocean. Both types of initial errors cause La Niña events to be under-predicted, inducing large prediction uncertainties in the Niño3 regions at the prediction time. It is found that the type-1 errors evolve like the growth phase of an El Niñolike event, while the type- 2 errors initially exhibit a rapid $\mathrm{La}$ Niña-like decay and then a transition to the growth phase of an El Niño-like event. The analysis of the developments of these initial errors shows that the Bjerknes positive feedback is the dominant factor favoring the rapid error growth during the spring season of the type- 1 errors. For the type- 2 errors, the equatorial ocean waves and the recharge process play important roles in the development of prediction errors.

Especially, we noticed that the SST prediction errors in the Niño3 region caused by the type-1 initial errors are owing to the upward transport of warm water from the subsurface ocean and its subsequent growth in the surface over the equatorial eastern Pacific. As for the type-2 errors, the growth of positive errors of the Niño3 SST originates from the initial positive errors in the subsurface layers of the western equatorial Pacific and the subsequent enlarged errors recharged from $10^{\circ} \mathrm{N}$ in the central Pacific. Therefore, the upper layers of the eastern equatorial Pacific, the lower layers of the western equatorial Pacific and the offequatorial regions around $10^{\circ} \mathrm{N}$ in the central Pacific can be the candidates for the areas of targeted observations for $\mathrm{La}$ Niña predictions. If we can improve the observation network in these areas by deploying targeted observations, La Niña forecasting skill may be greatly improved.

Duan and $\mathrm{Hu}$ (2016) have demonstrated that two types of SPB-related initial errors also exist for El Niño events (See Fig. 6 in Duan and Hu 2016) within the CESM model. Therefore, the SPB phenomenon for both El Niño and La Niña events can be caused only by the growth of initial errors, and the SPB-related initial errors possess particular spatial patterns. As mentioned in the introduction, El Niño and La Niña display prominent asymmetric features in many aspects due to the complicated nonlinear processes in both the atmosphere and ocean. We compare our results and those of Duan and $\mathrm{Hu}$ (2016) and find that the SPB phenomenon of El Niño and La Niña events also exhibit somewhat asymmetric features. Firstly, although the largest error growth 
tendency for El Niño and La Niña both occur in the AMJ/ JAS season, the growth rates in the AMJ for La Niña are not as significantly faster than other seasons as those for $\mathrm{El}$ Niño. Secondly, the prediction errors for La Niña are smaller than those of El Niño. Taking the prediction error of Niño3 index as an example, it is found that on average the absolute value of those for El Niño events is usually larger than $2{ }^{\circ} \mathrm{C}$ while that for La Niña is smaller than $2{ }^{\circ} \mathrm{C}$. That is to say, the initial errors often yield a larger prediction uncertainty for El Niño than La Niña. Therefore, compared with El Niño events, the predictions for La Niña events show a less prominent season-dependent evolution of prediction errors and a smaller prediction error at the prediction time, and hence a less significant SPB phenomenon. In fact, initially, the SPB is demonstrated basing on the Niño3 time series of all years, not separating El Niño, La Niña and neutral years (Webster and Yang 1992; Torrence and Webster 1998). This means that there may exist the SPB for both El Niño and La Niña predictions, but with different strength. El Niño and La Niña can be dynamically explained in the same framework, for example, recharge-discharge mechanism and delayed oscillator. However, there still exist asymmetries for the development of El Niño and La Niña, one of which is the amplitude asymmetry (An and Jin 2004; Su et al. 2010; Im et al. 2015). That is, the amplitude of SSTA in the eastern equatorial Pacific during El Niño is typically larger than that during La Niña episodes. In this sense, it may also indicate that the SPB of El Niño and La Niña bear different strength. Therefore, our work is somewhat consistent with these statements.

In addition, we also compare the spatial patterns of the two types of SPB-related initial errors for El Niño and La Niña events. The type-1 initial errors of La Niña are almost opposite to those of El Niño. For the type-2 errors, the error growth for El Niño predictions is confined in the equatorial regions while the La Niña predictions are also affected by the errors in the $10^{\circ} \mathrm{N}$ in the central Pacific. In this sense, additional observations in the equatorial regions (i.e. the upper layers of the eastern equatorial Pacific and the lower layers of the western equatorial Pacific) may greatly improve El Niño predictions, but the observations in the off-equatorial regions around $10^{\circ} \mathrm{N}$ in the central Pacific may be also necessary to improve La Niña predictions.

We demonstrate two types of SPB-related initial errors for La Niña events, which yield large prediction uncertainties and often cause an SPB of La Niña, and further identified potential areas of targeted observation from these errors. Here, the SPB-related initial errors were not obtained by optimization algorithm due to the complexity of the CESM model and related areas for targeted observations could not represent the most sensitive area for targeted observations associated with La Niña predictions. Since the two types of SPB-related initial errors were extracted from one hundred and eleven initial errors that yield SPB for La Niña, we can say the above SPB-related initial errors are often to cause SPB for La Niña prediction. Nevertheless, additional experiments should be conducted to examine the validity of the above potential areas for targeted observations with regard to improving the forecast skill of La Niña events. One can also directly use the approach of conditional nonlinear optimal perturbation (CNOP, Mu et al. 2003) to identify the most sensitive initial errors and related most sensitive areas for targeted observations for ENSO predictions. And a comparison between the most sensitive initial errors obtained by CNOP and the above SPB-related initial errors can be performed in future studies. It is expected that the comparison can demonstrate the usefulness of the areas for targeted observations revealed here in improving La Niña prediction skill. In addition, we suggested that the predictions for $\mathrm{La}$ Niña events bear a less significant SPB than El Niño, which indicates that the forecasting skill for El Niño may exhibit a faster decline across the boreal spring. However, it should be noted that we did not consider the effect of model errors. Actually, most of current models show a better performance in reproducing El Niño than La Niña events. This may be a reason why most of current models tend to show a higher forecasting skill for El Niño than La Niña in realistic/operational predictions (Jin et al. 2008). Nevertheless, how the model error affects the SPB and whether the characteristics of the initial errors that cause an SPB for La Niña events identified in this study would hold. These questions should be explored in-depth and the theoretical results should also be examined in future studies by conducting realistic hindcast experiments.

Acknowledgements This work was supported by the National Natural Science Foundation of China (Grant nos. 41690124, 41706016, 41525017 and 41606019), and National Programme on Global Change and Air-Sea Interaction (GASI-IPOVAI-06).

Open Access This article is distributed under the terms of the Creative Commons Attribution 4.0 International License (http://creativeco mmons.org/licenses/by/4.0/), which permits unrestricted use, distribution, and reproduction in any medium, provided you give appropriate credit to the original author(s) and the source, provide a link to the Creative Commons license, and indicate if changes were made.

\section{References}

An S-I, Jin FF (2004) Nonlinearity and asymmetry of ENSO. J Clim 17:2399-2412

Balmaseda MA, Davey MK, Anderson DLT (1995) Decadal and seasonal dependence of ENSO prediction skill. J Clim 8(11):2705-2715

Barnston AG, Tippett MK, L'Heureux ML, Li S, DeWitt D (2012) Skill of real-time seasonal ENSO model predictions during 2002-11: is our capability increasing? Bull Am Meteorol Soc 93:631-651

Barnston AG, Tippett MK, Ranganathan M, L'Heureux ML (2017) Deterministic skill of ENSO predictions from the North American 
Multimodel Ensemble. Clim Dyn. https://doi.org/10.1007/s0038 2-017-3603-3

Bjerknes J (1969) Atmospheric teleconnections from the equatorial pacific. Mon Weather Rev 97(3):163-172

Chen D, Zebiak SE, Busalacchi AJ, Cane MA (1995) An improved procedure for El Niño forecasting —implications for predictability. Science 269:1699-1702

Chen D, Cane MA, Kaplan A, Zebiak SE, Huang DJ (2004) Predictability of El Niño over the past 148 years. Nature 428(6984):733-736

Clarke AJ, Van Gorder S (1999) The connection between the boreal spring Southern Oscillation persistence barrier and biennial variability. J Clim 12:610-620

Duan WS, Hu JY (2016) The initial errors that induce a significant "spring predictability barrier" for El Niño events and their implications for target observation: results from an Earth System Model. Clim Dyn 11(46):3599-3615

Duan WS, Wei C (2012) The 'spring predictability barrier' for ENSO predictions and its possible mechanism: results from a fully coupled model. Int J Climatol 33(5):1280-1292. https://doi. org/10.1002/joc. 3513

Duan WS, Liu XC, Zhu KY, Mu M (2009) Exploring the initial errors that cause a significant "spring predictability barrier" for El Niño events. J Geophys Res 114:C04022. https://doi.org/10.1029/2008J C004925

Fan Y, Allen MR, Anderson DLT, Balmaseda MA (2000) How predictability depends on the nature of uncertainty in initial conditions in a coupled model of ENSO. J Clim 13(18):3298-3313

Ham YG, Rienecker MM (2012) Flow-dependent empirical singular vector with an ensemble Kalman filter data assimilation for El Nino prediction. Clim Dyn 39:1727-1738. https://doi. org/10.1007/s00382-012-1302-7

Hoerling MP, Kumar A, Zhong M (1997) El Niño, La Niña, and the nonlinearity of their teleconnections. J Clim 10(8):1769-1786

Hu JY, Duan WS (2016) Relationship between optimal precursory disturbances and optimally growing initial errors associated with ENSO events: implications to target observations for ENSO prediction. J Geophys Res Oceans. https://doi.org/10.1002/2015J C011386

Hu ZZ, Kumar A, Xue Y, Jha B (2014) Why were some La Niñas followed by another La Niña? Clim Dyn 42:1029-1042

Hu ZZ, Kumar A, Huang B, Zhu J, Zhang RH, Jin FF (2016) Asymmetric evolution of El Niño and La Niña: the recharge/discharge processes and role of the off-equatorial sea surface height anomaly. Clim Dyn 49(7-8):1-12

Hurrell JW, Holland MM, Gent PR, Ghan S, Kay JE, Kushner PJ, Lamarque JF, Large WG, Lawrence D, Lindsay K, Lipscomb WH, Long MC, Mahowald N, Marsh DR, Neale RB, Rasch P, Vavrus S, Vertenstein M, Bader D, Collins WD, Hack JJ, Kiehl J, Marshall S (2013) The community earth system model a framework for collaborative research. Bull Am Meteorol Soc 94(9):1339-1360

Im SH, An S-I, Kim ST, Jin FF (2015) Feedback processes responsible for El Niño-La Niña amplitude asymmetry. Geophys Res Lett 42:5556-5563

Jin FF (1997a) An equatorial ocean recharge paradigm for ENSO. Part I: conceptual model. J Atmos Sci 54(7):811-829

Jin FF (1997b) An equatorial ocean recharge paradigm for ENSO. Part II: a stripped-down coupled model. J Atmos Sci 54(7):830-847

Jin EK, Kinter JL, Wang B, Park CK, Kang IS, Kirtman BP, Kug JS, Kumar A, Luo JJ, Schemm J, Shukla J, Yamagata T (2008) Current status of ENSO prediction skill in coupled ocean-atmosphere models. Clim Dyn 31(6):647-664

Kay JE, Deser C, Phillips A, Mai A, Hannay C, Strand G, Arblaster JM, Bates SC, Danabasoglu G, Edwards J, Holland M, Kushner P, Lamarque JF, Lawrence D, Lindsay K, Middleton A, Munoz E, Neale R, Oleson K, Polvani L, Vertenstein M (2015) The
Community Earth System Model (CESM) large ensemble project: a community resource for studying climate change in the presence of internal climate variability. Bull Am Meteorol Soc 96(8):1333-1349

Kirtman BP, Shukla J, Balmaseda M, Graham N, Penland C, Xue Y, Zebiak S (2002) Current status of ENSO forecast skill: a report to the climate variability and predictability (CLIVAR) Numerical Experimentation Group (NEG). CLIVAR Working Group on seasonal to interannual prediction, $\mathrm{p} 31$

Kug JS, Ham YG, Kimoto M, Jin FF, Kang IS (2010) New approach for optimal perturbation method in ensemble climate prediction with empirical singular vector. Clim Dyn 35:331-340

Kug JS, Ham YG, Lee EJ, Kang IS (2011) Empirical singular vector method for ensemble El Niño-Southern Oscillation prediction with a coupled general circulation model. J Geophys Res 116:C08029. https://doi.org/10.1029/2010JC006851

Larson SM, Kirtman BP (2015) Revisiting ENSO coupled instability theory and SST error growth in a fully coupled model. J Clim 28:4724-4742

Larson SM, Kirtman BP (2016) Drivers of coupled model ENSO error dynamics and the spring predictability barrier. Clim Dyn 48:3631-3644

Latif M, Barnett TP, Cane MA, Flugel M, Graham NE, Vonstorch H, Xu JS, Zebiak SE (1994) A review of ENSO prediction studies. Clim Dyn 9:167-179

Lee HC, Kumar A, Wang W (2017) Effects of ocean initial perturbation on developing phase of ENSO in a coupled seasonal prediction model. Clim Dyn C7:1-21

Levine AFZ, McPhaden MJ (2015) The annual cycle in ENSO growth rate as a cause of the spring predictability barrier. Geophys Res Lett 42:5034-5041

Lopez H, Kirtman KP (2014) WWBs, ENSO predictability, the spring barrier and extreme events. J Geophys Res-Atmos 119:10114-10138

Luo JJ, Masson S, Behera S, Shingu S, Yamagata T (2005) Seasonal climate predictability in a coupled OAGCM using a different approach for ensemble forecasts. J Clim 18(21):4474-4497

McPhaden MJ (2003) Tropical Pacific Ocean heat content variations and ENSO persistence barriers. Geophys Res Lett 30(9):1480

McPhaden MJ, Zhang X (2009) Asymmetry in zonal phase propagation of ENSO sea surface temperature anomalies. Geophys Res Lett. https://doi.org/10.1029/2009GL038774

Moore AM, Kleeman R (1996) The dynamics of error growth and predictability in a coupled model of ENSO. Q J R Meteorol Soc 122:1405-1446

Mu M (2013) Methods, current status, and prospect of targeted observation. Sci China Earth Sci 56(12):1997-2005

Mu M, Duan WS, Wang B (2003) Conditional nonlinear optimal perturbation and its applications. Nonlinear Process Geophys 10(6):493-501

Mu M, Duan WS, Wang B (2007a) Season-dependent dynamics of nonlinear optimal error growth and El Niño-Southern Oscillation predictability in a theoretical model. J Geophys Res 112:D10113. https://doi.org/10.1029/2005JD006981

Mu M, Xu H, Duan WS (2007b) A kind of initial errors related to "spring predictability barrier" for El Niño events in ZebiakCane model. Geophys Res Lett 34:L03079. https://doi. org/10.1029/2006GL027412

Ohba M, Ueda H (2009) Role of nonlinear atmospheric response to SST on the asymmetric transition process of ENSO. J Clim 22:177-192

Okumura YM, Deser C (2010) Asymmetry in the duration of El Niño and La Niña. J Clim 23:5826-5834 
Okumura YM, Ohba M, Deser C, Ueda H (2011) A proposed mechanism for the asymmetric duration of El Niño and La Niña. J Clim 24:3822-3829

Smith TM, Reynolds RW, Peterson TC, Lawrimore J (2008) Improvements to NOAA's historical merged land-ocean surface temperature analysis (1880-2006). J Clim 21:2283-2296

Su JZ, Zhang RH, Rong XY, Li T, Kug JS, Hong CC (2010) Causes of the El Niño and La Niña amplitude asymmetry in the equatorial eastern Pacific. J Clim 23(3):605-617

Tippett MK, Barnston AG, Li SH (2012) Performance of recent multimodel ENSO forecasts. J Appl Meteorol Climatol 51:637-654

Torrence C, Webster PJ (1998) The annual cycle of persistence in the El Niño Southern Oscillation. Q J R Meteorol Soc 124(550):1985-2004

Webster PJ (1995) The annual cycle and the predictability of the tropical coupled ocean-atmosphere system. Meteorol Atmos Phys 56:33-55

Webster PJ, Yang S (1992) Monsoon and ENSO: selectively interactive systems. Q J R Meteorol Soc 118(507):877-926

Xue Y, Cane MA, Zebiak SE, Blumenthal MB (1994) On the prediction of ENSO - a study with a low-order Markov model. Tellus A 46(4):512-528

Xue Y, Chen M, Kumar A, Hu Z, Wang W (2013) Prediction skill and bias of tropical Pacific sea surface temperatures in the NCEP Climate Forecast System version 2. J Clim 26(15):5358-5378

Yu JY (2005) Enhancement of ENSO's persistence barrier by biennial variability in a coupled atmosphere-ocean general circulation model. Geophys Res Lett 32:L13707. https://doi. org/10.1029/2005GL023406
Yu JY, Kao HY (2007) Decadal changes of ENSO persistence barrier in SST and ocean heat content indices: 1958-2001. J Geophys Res 112:D13106. https://doi.org/10.1029/2006jd007654

Yu YS, Duan WS, Xu H, Mu M (2009) Dynamics of nonlinear error growth and season-dependent predictability of El Niño events in the Zebiak-Cane model. Q J R Meteorol Soc 135:2146-2160

Zebiak SE, Cane MA (1987) A model El Niño-Southern Oscillation. Mon Weather Rev 115(10):2262-2278

Zhang T, Sun DZ (2014) ENSO asymmetry in CMIP5 models. J Clim 27(11):4070-4093

Zhang T, Sun DZ, Neale R, Rasch PJ (2009a) An evaluation of ENSO asymmetry in the community climate system models: a view from the subsurface. J Clim 22:5933-5961

Zhang WJ, Li JP, Jin FF (2009b) Spatial and temporal features of ENSO meridional scales. Geophys Res Lett 36:L15605

Zhang T, Perlwitz J, Hoerling MP (2014) What is responsible for the strong observed asymmetry in teleconnections between $\mathrm{El}$ Niño and La Niña? Geophys Res Lett 41:1019-1025. https://doi. org/10.1002/2013GL058964

Zhang J, Duan WS, Zhi XF (2015) Using CMIP5 model outputs to investigate the initial errors that cause the "spring predictability barrier" for El Niño events. Sci China Earth Sci 58(5):1-12

Publisher's Note Springer Nature remains neutral with regard to jurisdictional claims in published maps and institutional affiliations. 